\title{
BESCHRIJVING VAN DE ABLUTIE VÓÓR HET HUWELIJK IN SIMALOENGOEN (S. O. K.).
}

DOOR

\author{
G. L. TICHELMAN.
}

Voordat de Radja van het gebied Raja zijn bruid, een dochter van den Radja van het rijk Panei, naar zijn land voerde, teneinde haar te huwen en tot hoofdvrouw (poeang bolon) te verheffen, had te Pamatang Panei, zetel van den vorst van Panei, de plechtigheid plaats der ritueele wassching van de bruid. $Z_{\mathrm{ij}}$ 'toch moest magisch worden ontdaan van alle onzuiverheden en een bescherming in haar leven mede krijgen tegen invloeden, die haar geluk zouden kunnen bedreigen.

Het bruidspaar begaf zich in de ochtenduren, omstuwd door verwanten en aanverwanten naar het nabij de residentie (pamatang) stroomende riviertje, waar zij werden opgewacht door den priester (datoe), zijn helper en tal van belangstellenden.

In aller bijzijn werd thans het ritueele beschermingsreinigingsvocht (anggir pagar parsoesian) door den datoe gemengd.

Hij bezigde daartoe de volgende ingrediënten:

A. Vijf stuks oettei moekkoer, een citroensoort (Mal.: limau poeroet), onderscheidenlijk:

1. sada naloppou djoengdjoengan (één uit het hoogste topje van den citroenboom).

2. sada na doppak Hataran (één, die aan den boom naar het Oosten was gekeerd).

3. sada na doppak Oetara (één, die aan den boom naar het Noorden was gericht).

4. sada na doppak Pastima (één, die aan den boom naar het Westen was gekeerd).

5. sada na doppak Dangsina (één, die aan den boom naar het Zuiden was toegewend).

B. Zeven verschillende soorten bladeren en van elke soort zeven stuks. Deze soorten zijn : 
1. sorba salah; 2. salah nipi; 3. sibalik angin; 4. sibalik hoenda;

5. sibalik hoemosing; 6. sakkil sipilit; 7. silandjoejang.

C. Vier bosjes bloemen, bestaande uit: 1. roedang sigerger (een roode bloem); 2. roedang sigorsing (een gele bloem); 3. roedang rochoe-roehoe, een violette bloem (Ocimum sanctum. L.). Aan elk bosje wordt nog toegevoegd: een geheel toebereid slechts in de lengte gevouwen sirih-pruimpje (apoeran sajoer), gele rijst (boras binorna) en eenige druppeltjes van de onvermijdelijke minak saloh (een olie geperst uit een takje van den citroenboom, dat gebrand werd en daarna op een stuk ijzer gedrukt).

Dit alles was reeds van te voren ter toebereiding aan den priester overhandigd.

A. De citroenen had hij op een bepaalde wijze voorzien van incisies, waarin hij stukjes zeer oude curcuma had gestoken.

1. De uit den top van den boom geplukte citroen kreeg zeven kleine, evenwijdige insnijdingen.

2. De citroen, die aan den boom naar het Oosten was gekeerd, eveneens.

3. De naar het Noorden gerichte citroen was in twee deelen gesneden.

4. Op de schil van de naar het Westen gekeerde citroen was een bepaald afweerteeken (de bindoe matogoeh) gesneden.

-5. De naar het Zuiden toegewende citroen was in schijfjes gesneden.

B. De zeven verschillende soorten bladeren waren ieder in zeven reepjes gekerfd.

Dit alles bijeen gevoegd in één groote, melkwitte kom, werd vervolgens bewierookt, waarbij het volgende tooverformulier werd uitgesproken :

„Ase toeroen ma hamoedei Debata di atas, manangkih hamoedei "Debata di toroeh, hoemoendoel hamoedei Debata di tongah, satongah „,oeroen ham pangoeloebalangkoe, pangoeloebalang ni pandahoepai. „Ase marsapsap marmangmang marmintori mangasap mardahoepa „,hoeasap hoedahoepai anggir pagar parsoesian ni booe on, na so „dapot haboeboekan, na so dapot halajoean, na so dapot habangkeian "pinagarankon."

(Vrij vertaald: „Komt af, Gij Goden der Bovenwereld. Stijgt op, Gij Goden der Onderwereld! Neemt plaats, Gij Goden van het Midden. Blijf zweven beschermgeest van het dorp; beschermgeest van dengene, die de wierook laat branden. Opdat de rook moge 
ontstaan, het bezweringsformulier uitgesproken worden, de rook opstijgen, de wierook haar geur verspreiden. Ik berook met wierook dit beschermingsreinigingsmiddel der Prinses, die maagdelijk, onaantastbaar en onsterfelijk, door mij bediend wordt met dit beschermmiddel.")

Toen de bruid aan het riviertje was gearriveerd, nam de priester zeven handenvol zand, waarvan hij aan den oever van het stroompje een hoopje formeerde, waarop de kom werd geplaatst.

De priester kneedde vervolgens alle bestanddeelen dooreen (pangir), daaraan met de hand zeven schepjes water toevoegend. Het mengsel werd alsdan gezeefd door het tweede omhulsel van de bloesem van de klapperboom (salodang) en zoodoende werd het zuivere, voor het onderhavige doel geëigende wijwater (anggir pagar parsoesian) verkregen.

De daarover alsdan ingeroepen zegen luidde als volgt:

„Ase toeroen ma hamoedei Debata di atas, manangkih ma hamoedei Debata di toroeh, hoemoendoel ma hamoedei Debata di tongah, satongah toeroen ham pangoeloebalangkoe, pangoeloebalang ni pagar parsoesian. Ase marsoek sama marsoentabi do ahoe padjongdjong anggir pagar parsoesian ni booe on. Ia goran ni oettei on, ai ma soeansoeanan ni oppoeng botara goeroe, goran ni hoening panilipi on Toean di Haboehoeran, goran ni paranggiran on, si Djotima, goran ni tappeianni on, Poeang Saksak na Idjou, goran ni bah on, si Dajang Loemistang, $i$ hoeloean Radja Manoesoer Goenoeng, $i$ kahean Radja. Monggak di Laoet, goran ni sampoeran si Andorang, goran ni batoe si Radja Goemilang, goran ni ari na siang on Radja Dïn Ganas, goran ni ari na golap Radja Djin Salemboet, goran $n i$ bittang Radja Djin Katip, pakkon goran ni logou Radja Djin Salioer. Doengma hoeasal nasiam, ase goran ni tanoh gan hapeini Radja Tobal Doenia. Ara-ara doemillah moela djadi, djadi darih kepada Toean-toean manikat maoen di irisan kajoe siramboenei naraskon ahoe toeboeh, mintori sidajang minoellah sonti panoenggoeng, sonti pangori, aselah salamat ahoe $i$ pagari anggir pagar parsoesian on. $O$ simangka homi oelang ipandang ho minakkoe. Ia ipandang ho minakkoe, malahlah malohloh ma ho begoe! $O$ assoebah boeloeh laga, oelang ho maleisei-lissei, ompoeng sinoembah nalanggatan sahoelahoela sabaoebaoe oelang nasiam maniseinisei bani pinagarankon."

(Vrij vertaald: „Komt af, Gij Goden der Bovenwereld! Stijgt op, Gij Goden der Onderwereld! Neemt plaats; Gij Goden van het 
Midden. Blijf zweven beschermgeest; geest van het beschermingsreinigingsmiddel. Ik zend dit gebed op en smeek $U$ ootmoedig, verontschuldig mij, dat ik dit beschermingsreinigingsmiddel van deze Prinses toebereid. De naam van de citroen is : plant van den Grootvader Botara Goeroe. De naam van de op de slapen te strijken curcuma is: Heer Dihaboehoeran. De naam van de wijwaterkom is : Si Djotima. De naam van het hoopje zand, waarop de kom wordt geplaatst is: Wit-groene Heer. De naam van dit water is: Si Dajang Loemistang; aan den bovenloop is het de Vorst, die van de bergen daalt; aan den benedenloop de Vorst, die het hoofd boven het zeewater houdt. De naam van den waterval is: Si Andorang. De naam van den steen is: Vorst Goemilang (Schitterende Vorst). De naam van dezen helderen dag is: Vorst wilde Demon. De naam van den duisteren dag is: Vorst Nachtwade. De naam van de ster is: Vorst Demon Katip, mitsgaders de naam van den Wind: Vorst Demon van de klaarte. Reeds heb ik $U$ naar $U_{w}$ oorsprong doorgrond, voorts moet de naam der aarde waarlijk luiden: Vorst Dikke Wereld.

Het uitvloeiend eerste vruchtwater; het begin van het ontstaan van en tot den mensch; het vastleggen der toekomst, in het NoordOosten de door den geest bewoonden Siramboenei-boom, die met mij geboren is, tooverformulier, vrouwelijke geest vertrouwde Gods, Verhevene, Waardige, die Vreeze inboezemt, opdat ik zegen verkrijg van dit beschermingsreinigingsmiddel. O! Simangka Homi, maak mijn olie niet werkeloos. Wanneer Gij mijn olie werkeloos maakt, zult Gij vermorzeld worden, Geest. O! boeloeh laga (een soort bamboe), watervat, Gij moogt niet vervreemden. Vereerde en gevreesde Voorvaderen der verwanten- en aanverwantengroepen, laat niet af van mijn beschermelinge".)

De bruid, voor wie het middel was bereid, nam eindelijk op aanwijzing van den datoe vier teugen van het mengsel. Bij den eersten teug boog zij zich diep voorover; bij den tweeden wierp zij het hoofd achterover en blikte naar boven; bij den derden keek zij naar rechts; bij den vierden naar links.

Tenslotte nam de bruid een weinig van het mengsel met de hand uit de kom en bevochtigde daarmede het voorhoofd en haar. Deze handeling werd nagevolgd door den bruidegom en alle familieleden, vrienden en belangstellenden (ook Europeanen), die daaraan wenschten deel te hebben. Voor hen, die zich mede met het wijwater besprenkeld hadden, was een rood-gevederde haan geslacht, in een bamboe toebereid en daarna in stukken gesneden, welke weder in 
den vorm van dit dier bijeen gevoegd waren op een oud bord, pinggan djarodjak geheeten. Daarbij werden op een melkwitte schaal twee soorten meelkoeken opgediend, de nitak binonggar en de botara goeroe, alsmede een gekookt ei, de hybiscusbloem (boenga raja), gember en wat zout, gewikkeld in een boven het vuur weekgemaakt pisangblad.

Het vorenbeschreven ceremonieel betrof het afhalen van de hooge bruid, waarbij allerlei openbare feestelijkheden plaats vonden.

De eigenlijke sluiting van het huwelijk zou daarna plaats vinden, zonder eenig vertoon. Dit ceremonieel bestaat uit het elkander toereiken van een handvol gekookte rijst en eenige toespijzen, welke handeling met de grootste omzichtigheid behoort te worden verricht, want wanneer een korrel rijst gespild wordt, beteekent zulks den dood van een kind. Hiermede kan pas het huwelijk als voltrokken beschouwd worden.

De Radja van Raja, Toean Gomok, was drie jaren te voren door het Gouvernement als. Zelfbestuurder erkend, doch hij was nog steeds niet volgens de adat tot Radja gekroond. $\mathrm{Nu}$ hij zich een hoofdvrouw had genomen kon de kroning volgens de adat (manradjahon) eenigen tijd daarna plaats vinden, waarbij feestelijkheden en maaltijden voor de bevolking worden aangericht.

Eerst na de verheffing volgens de adat tot Radja van den tegenwoordigen Zelfbestuurder kan de op 1 Januari 1933 overleden vorigen Zelfbestuurder, Toean Kapoltakan, worden ter aarde besteld. Zijn stoffelijk overschot bevindt zich thans nog boven de aarde in een apart huisje (tandoeran) en hij wordt verondersteld nog te slapen (modom). Thans kan hij de eeuwige rust ingaan.

Ook zijn gemalin, de vorige poeang bolon, die eenigen tijd voor den Radja was overleden en die naast haar echtgenoot nog boven de aarde staat, kan, nu er een vervangster is, begraven worden. 